\title{
SOCIAL MYTHOLOGY IN POLITICS ${ }^{1}$
}

\author{
Andrey G. Ivanov \\ Lipetsk Branch of Russian Presidential Academy of National Economy and Public Administration, \\ Lipetsk, Russian Federation
}

\begin{abstract}
The article shows the link between social mythology and ideology. Modern social mythology and political ideology are presented as similar in mechanism of penetration into the public consciousness phenomena capable of being significant contributors to socio-political development. In social mythology there are two levels "archaic" and "opportunistic" ("instrumental"). Duplex measurement of social mythology is evident in the functioning of the "global" myths. So, for example, the myth of the hero trends of transformation of social mythology today are demonstrated. The mythology of the images of Stalin in the context of transformation of contemporary social mythology is analyzed: changes in many dimensions are revealed - the ontological, axiological, praxeological. The social mythology is influenced by both internal (internalist) factors and the specific context (externalist factors): social and cultural environment, political situation. The article notes the resemblance of ideology and social mythology. A key criterion in determining the difference between the social mythology and ideology, is not the method of transmission, mechanism of action and targets, and not even the context and the content itself but the content of these phenomena. If the content of social mythology has depth, goes back to antiquity, the ideology only trying to "imitate" the myth, using its capacity to service current, market interests. Despite the fact that the main functions of social mythology in general positive, the penetration of social myths in the scope of the policy will always bear the threat to social development. Currently, the policy becomes relevant predictive function of social mythology and it is important that the public demand for a new social mythology was felt by political elites and transformed into tangible programs and concrete actions. Consideration and comparison of the features of social mythology and, in particular, political myths lead to the conclusion of the dual and contradictory role of social mythology in politics and in society in general. Public demand for a new social mythology and ideology should be felt by political elites and transformed into tangible programs and concrete actions.
\end{abstract}

Key words: social mythology, ideology, political myth, "archaic" and "conjunctural" ("instrumental") levels of social mythology, "global" myth, myth of the hero.

УДК 101.1

ББК 87.63

\section{СОЦИАЛЬНАЯ МИФОЛОГИЯ В ПОЛИТИКЕ ${ }^{1}$}

\author{
Андрей Геннадиевич Иванов \\ Липецкий филиал Российской академии народного хозяйства и государственной службы \\ при Президенте Российской Федерации, г. Липецк, Российская Федерация
}

\begin{abstract}
Аннотация. В статье показана связь между социальной мифологией и идеологией. Современная социальная мифология и политическая идеология представлены как похожие по механизму проникновения в общественное сознание феномены, способные быть существенными факторами социально-политического б развития. В социальной мифологии выделяются два уровня - «архаический» и «конъюнктурный» («инструментальный»). Двухуровневое измерение социальной мифологии ярко проявляется в функционировании «глобальных» мифов. Так, на примере мифа о герое продемонстрированы тенденции трансформации соци。 альной мифологии сегодня. Проанализирована мифология образов И.В. Сталина в контексте трансформа๘ ции современной социальной мифологии: выявлены изменения во многих измерениях - онтологическом, аксиологическом, праксиологическом. На изменение социальной мифологии оказывают влияние как внут(?) ренние (интерналистские) факторы, так и определенный контекст (экстерналистские факторы): социокуль-
\end{abstract}


турная среда, политическая ситуация. В статье отмечается внешнее сходство идеологии и социальной мифологии. Ключевым критерием, определяющим отличие между социальной мифологией и идеологией, выступает не способ трансляции, механизм воздействия и адресаты, и даже не контекст, а само содержание, наполнение этих явлений. Если содержание социальной мифологии имеет глубину, восходит к архаике, то идеология лишь пытается «подражать» мифу, используя его потенциал в обслуживании текущих, конъюнктурных интересов. Несмотря на то что основные функции социальной мифологии в целом позитивны, проникновение социальных мифов в сферу политики всегда будет нести угрозы для общественного развития. В настоящее время в политике актуальной становится прогностическая функция социальной мифологии, и важно, чтобы общественный спрос на новую социальную мифологию ощущался политическими элитами и трансформировался в осязаемые программы и конкретные действия. Рассмотрение и сравнение функций социальной мифологии и, в частности, политических мифов приводит к выводу о двойственной и противоречивой роли социальной мифологии в политике и обществе в целом. Общественный запрос на новую социальную мифологию и идеологию должен ощущаться политическими элитами и трансформироваться в осязаемые программы и конкретные действия.

Ключевые слова: социальная мифология, идеология, политический миф, «архаический» и «конъюнктурный» («инструментальный») уровни социальной мифологии, «глобальный» миф, миф о герое.

Идеологией осуществляется активное использование ряда свойственных мифу характеристик, что наглядно демонстрируется на примере мифотворческой деятельности. В частности, Г.Н. Оботурова полагает, что распространение идеологии было крайне важно для мифа: «...мощным фактором утверждения мифологического сознания в массах является идеологическое “навязывание”, сознательная экспансия в обыденное сознание определенных идеалов и ценностей» [10, с. 29].

Для легитимации какой-либо идеологии желательно стремиться к такому положению дел, когда основная масса населения станет считать идеологию «своей», соответствующей собственным ожиданиям, внутреннему мироощущению и надеждам. Зачастую так происходит в случае использования мифов в политической сфере: политические субъекты исходят из того, что какие-то измерения мифов могут оказаться близкими человеку, фундаментальными для него. Все это приводит к глубокому проникновению политической мифологии в структуры общественного сознания, особенно если речь идет об этиологических мифах. Применительно к России здесь можно привести пример мифа о смутном времени как периоде, предваряющем рождение и строительство нового государства. При этом не важно, о каком периоде идет речь - о Смуте конца XVI - начала XVII в., о революциях начала XX в. или же о развале СССР, - характерной чертой являются общественные умонастроения, связанные с ожиданием чего-то значимого и грандиозного, касающегося каж- дого жителя. Не последнюю роль в таком процессе играет отмечаемая Р. Бартом бесконечная суггестивность мира [1].

Важность рассмотрения политической идеологии подтверждается глубоким выводом американского антрополога К. Гирца, который, в одной из своих статей рассматривая государства так называемого третьего мира, пришел к выводу, что там вместо детализированных мифов, разработанных ритуалов стали использоваться комплексные представления, обладающие большей абстрактностью, произвольностью и аргументированностью: «Записанные ли в официальной конституции, воплощенные ли в новой совокупности институтов государственного управления, возведенные ли в ранг универсального вероучения (или, что не редкость, сразу во всех трех видах), эти представления, которые я назвал бы идеологией в собственном смысле этого слова, играют ту же самую роль, какую до этого играли гораздо менее теоретически разработанные доидеологические представления, преемниками которых они являются» [2, с. 395]. Стоит отметить, что К. Гирц допускал довольно сильное влияние вышеупомянутых комплексных представлений, считая, что в XX в. на жизнь государств более сильное влияние оказывают культурные традиции и производные от них идеологические установки, чем системы управления обществом и государством с соответствующими исторически наследуемыми организационными особенностями.

Далее рассмотрим определение идеологии и ее связь с социальной мифологией (пре- 
имущественно в части мифотворчества) и политикой в целом.

Идеологию принято определять следующим образом: «Идеология - понятие, посредством которого традиционно обозначается совокупность идей, мифов, преданий, политических лозунгов, программных документов партий, философских концепций; не являясь религиозной по сути, идеология исходит из определенным образом познанной или “сконструированной” реальности, ориентирована на человеческие практические интересы и имеет целью манипулирование и управление людьми путем воздействия на их сознание» [3, с. 405].

Общественное сознание, таким образом, оказывается главным предметом идеологического воздействия. Во времена бурных социальных преобразований общественное сознание становится крайне уязвимым перед разного рода идеями, часто далекими от рационального наполнения. Интересно, что от способности государства держать под контролем такие идеологизированные общественные представления (назовем это идеологической функцией государства) зависит в итоге эффективность самого администрирования и государственного управления в целом.

В XX в. идеология стала интерпретироваться главным образом через политическое преломление, атрибутивными характеристиками чего оказывались пропагандистские и агитационные компоненты.

Отдельно стоит отметить, что термин «идеология» сегодня часто употребляется в негативном смысле. Это объясняется историческими событиями, бросившими тень на само понятие идеологии: коммунизм, германский национал-социализм. По этой же причине затруднено и обсуждение темы «политика и миф».

Специфика сегодняшних идеологий связана с тем обстоятельством, что в настоящее время нередко имеет место взаимопроникновение между идеологиями и различными политическими программами, что фактически делает невозможным проведение четкой демаркационной линии между сферами политики и идеологии. В результате мы начинает считать идеологически заданными любые внятные траектории политического поведения.
Во многих странах современного мира можно зафиксировать отсутствие реального непосредственного воздействия идеологических составляющих на функционирование государства и общества. Это объясняется широким распространением отлаженно работающих демократических институтов и процедур, обеспечивающих действенность так называемой системы сдержек и противовесов, в частности при принятии тех или иных определяющих политических решений. При этом скорее исключениями являются государства с тоталитарным и авторитарным политическим режимом, в которых идеологическое воздействие приобретает четкие, институционализированные формы, зачастую восходящие к эпохам становления государства в целом или отдельных его социальных классов.

Нельзя сбрасывать со счетов и мнение о возникновении идеологии вместе с классовым обществом, в результате чего идеология начинает характеризоваться как обслуживающая интересы определенного класса. В частности, К. Маркс отмечал следующее: «Класс, имеющий в своем распоряжении средства материального производства, располагает вместе с тем и средствами духовного производства, и в силу этого мысли тех, у кого нет средств для духовного производства, оказываются в общем подчиненными господствующему классу» [8, с. 430].

Далее уже к М. Селиджеру [19] восходит традиция разграничения фундаментальной идеологии, предстающей в теоретических трудах, и идеологии оперативной, состоящей в системе аргументации, которая поддерживает проводимую политику.

Обобщая идеи М. Селиджера, К. Флад приходит к выводу, что фундаментальная и оперативная идеология структурно схожи, с тем лишь различием, что «...если в фундаментальной идеологии доминируют предписания морального характера (основные аксиомы, ценности, конечные цели), то в оперативной идеологии не меньшее, а то и большее значение приобретают технологии, то есть принципы действия» [14, с. 24].

Кроме того, К. Флад задается вопросами о содержании взаимосвязи между идеологией и формированием реальной политики, полагая, что ориентация идеологии на практические действия 
становится причиной ее связи с организованными участниками политической жизни, например с партиями или прессой [14, с. 24].

Вслед за М. Селиджером и К. Фладом ряд исследователей $[12 ; 18]$ также, но уже под несколько иным углом зрения, выделяет в идеологии два уровня - ценностно-нормативный и операциональный. При этом ценностно-нормативный уровень охватывает идеальные универсальные конструкции (публикации, рукописи и тексты, которые имеют существенное значение для общества) и «сильное ядро утопического мышления» [12, с. 135]; операциональный уровень идеологии охватывает повседневную жизнь, социальную психологию, обобщенно выражающие «...устойчивое образование типа социального или национального характера, а также нравы, традиции, обычаи, вкусы» [12, с. 136].

Тесную связь двух отмеченных выше уровней идеологии В.Н. Первушина характеризует следующим образом: «Идеология не может стать универсальной, если не "овладеет массами", а ее ценностно-нормативное ядро не будет воспринято, если оно не пережито на уровне группового и индивидуального поведения, не станет привычкой и не трансформируется в обычаи и традиции, не будет проявляться в массовых типичных ситуациях рутинной жизни, не приобретет характера стереотипа» $[12$, с. 136].

В современной социальной мифологии, на наш взгляд, можно выделить два уровня «архаический» и «конъюнктурный» («инструментальный»). Как и в случае с идеологией, между выделенными уровнями существует тесная взаимосвязь, происходит постоянное взаимодействие. Фактически (учитывая, что «конъюнктурный» («инструментальный») уровень почти тождественен современным политическим идеологическим конструктам) речь идет о постоянном взаимодействии мифологии и идеологии в каждом социальном мифе. Такое взаимодействие и составляет главную особенность проявления социальной мифологии в политике. Наглядные иллюстрации специфики функционирования социальной мифологии в политической сфере дают нам примеры таких мифов, влияющих на практику государственного управления и политические процессы, как имперский миф и миф о герое. Та- кого рода мифы можно назвать «глобальными», так как они достаточно органично осуществляются на двух вышеуказанных уровнях. Так, миф о герое, актуальный и востребованный в той или иной степени практически на протяжении всей истории развития общества, имеет следующее строение: во-первых, центральный компонент архетипического образа (происхождение, качественные характеристики, роль героя, его взаимодействия со сверхъестественными силами, его борьба с врагами, путь испытаний героя), который относится к «архаическому» уровню социальной мифологии; во-вторых, определенные коннотации образа, обусловленные сиюминутными общественными практиками, что относится уже к «конъюнктурному» («инструментальному») уровню социальной мифологии. Более того, некоторые исследователи усматривают характерные особенности, свойственные российскому общественному сознанию, в котором героический миф обнаруживает в себе целый ряд новых черт: «Герой - это всегда лидер протеста против бездушной государственной машины, которую он ради общего блага призван победить и подчинить своей воле» $[11$, с. 98$]$. Ярким примером мифа о герое, позволяющим увидеть специфику развертывания «глобального» социального мифа в современной российской действительности, является миф о И.В. Сталине [5]. Интересно, что происходящая в последние годы трансформация мифологии образов Сталина дает возможность на практике выделить ряд тенденций в развитии социальной мифологии: изменения обнаруживаются во многих измерениях - онтологическим, аксиологическом, праксиологическом.

Трансформации в структуре социальной мифологии (прежде всего «перемещение» представлений о каузальной связи и об отношении части с целым на глубинный - «архаический» - уровень) на примере мифологии образа Сталина проявляются в объяснении его поступков некой высшей волей.

Касаясь распространяющихся в последнее время тенденций оценивать степень конструктивности или деструктивности последствий социальной мифологии, следует упомянуть, что в современном обществе, на наш взгляд, одним из немногих феноменов, не ус- 
тупающих по значительности, интенсивности праздникам архаических обществ, является война как их противоположность. Учитывая данное соображение, не должно вызывать удивления то обстоятельство, что в последнее время образ Сталина устойчиво ассоциируется в массовом сознании россиян с победой в Великой Отечественной войне, и во многом в связи с этим фактом мифология образа Сталина может расцениваться как аксиологически позитивно окрашенная.

Праксиологические измерения социальной мифологии, представленные прежде всего мифоритуальными практиками, сегодня демонстрируют следующее: медленно, но необратимо утрачивается связь с традициями и ценностями. При этом сами мифоритуальные практики, с развитием общественных отношений отрываясь от изначально присущей им синкретичности, предстают теперь уже как рационализированная, регламентированная форма социального поведения. Такие практики с успехом выступают в качестве предмета коммерциализации, чему способствует динамично развивающаяся в последнее время индустрия памяти. В случае с образом Сталина происходит его тиражирование в массовой культуре, что заставляет вспомнить о схеме Р. Барта, где миф выступает в качестве вторичной семиологической системы.

Таким образом, пример трансформации мифологии образа Сталина наглядно показывает складывающиеся тенденции развития социальной мифологии, фактически подтверждая их. Исключение здесь составляет гносеологическое измерение (возможно, в данном случае сказывается специфика функционирования именно «глобального» мифа, к которому мы отнесли миф о герое). Примечательно при этом, что такие возможные изменения гносеологического плана, происходящие в ряде других социально-мифологических проявлений, как постепенная элиминация сферы действия принципа синкретизма, деградация потенциала символа и кризис классических идеологий, не показательны в случае мифологии образа Сталина. Здесь фигура вождя выступает в качестве одного из последних оплотов той социальной мифологии, которая еще не успела претерпеть столь фатальные изменения. Именно поэтому, на наш взгляд, сегодня представители ряда российских политических партий пытаются «ухватиться» за образ Сталина, все еще способный консолидировать определенную часть населения, не утративший глубокого символического значения и даже продолжающий сохранять в себе известную долю синкретизма, где все взаимосвязано: например, все, к чему прикасается вождь, успешно решается, будь то борьба с коррупцией или военные и политические успехи.

Кроме того, следует отметить, что на изменение социальной мифологии оказывают влияние как внутренние (интерналистские) факторы, так и определенный контекст (экстерналистские факторы): социокультурная среда, политическая ситуация. В случае с фигурой Сталина, катализаторами трансформации соответствующей социальной мифологии, выступили радикальные перемены, произошедшие в нашей стране в последние тридцать лет. Распад СССР, усталость от демократических перемен и, как закономерный итог, неустойчивость и спонтанность развития постсоветского общества, привели к росту пессимистических общественных настроений. В результате можно констатировать феномен кризисного сознания, включающего социальные страхи, социальные иллюзии, общественную ностальгию. Диагностирование такого кризисного сознания, охватившего как широкие массы граждан нашей страны, так и, что немаловажно, политическую элиту, объясняет популярность образа вождя: этим образом вполне могла воспользоваться элита для своих политических целей, для реализации своих политических амбиций, построив на основе мифа о герое соответствующую идеологическую конструкцию.

Дополнительным подтверждением значимости социального мифа и, в частности, такой его разновидности, как политический миф, служит мнение М. Штейнман, которая полагает, что существенная часть политических мифов тесно связана с концепцией славы, прежде всего государственной: «Эта слава может рассматриваться как утерянная (развал СССР) или же возрожденная (вхождение Крыма в состав Российской Федерации в 2014 году). Концепции славы и победы (прежде всего победы в Великой Отечественной 
войне) настолько тесно связаны в российском политическом дискурсе, что все заметнее становится процесс своего рода их присвоения истеблишментом» [20, p. 96].

Современная мифология и идеология имеют ряд общих характеристик, позволяющих рассматривать их в определенном смысле как схожие феномены, способные быть важными факторами социально-политического развития. С одной стороны, идеология занимает значительное место в современной социальной мифологии, фактически определяя содержание выделяемого нами «конъюнктурного» уровня социальной мифологии. Это сближает социальную мифологию с любой из современных форм общественного сознания, особенно с политической. С другой стороны, на теоретическом уровне общественного сознания осуществляется как бы использование или своеобразная эксплуатация свойственных мифу черт и характеристик, что наглядно можно увидеть на примере мифотворческих процессов.

Далее можно отметить распространенное мнение о том, что миф, как и идеология, принадлежит определенной группе. Такое мнение разделял X. Тюдор, характеризуя политический миф как нарратив конкретной группы, у которой есть свои герои, представляющие соответствующую группу и символизирующие политическую судьбу общности [21].

Определение Б. Линкольном [17] мифа как идеологии в нарративной форме и мнение К. Флада [14] о том, что миф представляет собой идеологически маркированный нарратив, продолжают традицию рассмотрения мифа и идеологии как фактически синонимичных феноменов, но также и открывают простор для рассуждений о повествовательной форме мифа.

Справедливым представляется утверждение, что идеология и миф являются отличающимися друг от друга, но взаимодополняющими видами политических текстов, которые используют различные механизмы воздействия: «... рационально-логическую аргументацию, призванную убедить, - в случае идеологии и хронологическое изложение, позволяющее представить нечто как очевидное, - в случае мифа» [7, с. 9].

Нарративная форма мифа, однако, оказывается почти всеохватывающей, и здесь мы соглашаемся с Р. Бартом, полагавшим, что «...носителем мифического слова способно служить все - не только письменный дискурс, но и фотография, кино, репортаж, спорт, спектакли, реклама. Миф не определяется ни своим предметом, ни своим материалом, так как любой материал можно произвольно наделить значением...» [1, с. 234].

При этом миф не просто наделяет вещи значением и смыслом, но и, в отличие от других символических форм, придает вещам значимость (significance), делая их близкими человеку [16, p. 123-124].

В целом, соглашаясь с мнением вышеуказанных исследователей, отметим также, что критерием, определяющим отличие между социальной мифологией и идеологией, выступает не способ трансляции, механизм воздействия и адресаты, и даже не контекст, а само содержание, наполнение этих явлений: содержание социальной мифологии обладает глубиной, восходит к архаике, а идеология пытается только «подражать» мифу, используя его потенциал в обслуживании текущих интересов, замыкаясь в актуальной современности.

Конечно, для общества всегда будет существовать потенциально высокий уровень угрозы от проникновения социальных мифов в сферу политики. Однако фиксация данного обстоятельства не означает обязательно того, что социальный миф в политической сфере, в политических институтах выполняет исключительно негативные, деструктивные функции. Так, встречаются точки зрения, абсолютизирующие конструктивное значение идеологии именно в связи с мифом: «Миф, воспринимаемый как иносказание о коллективном опыте, не может сам по себе исказить идеологию, наоборот - только он в полной мере способен насытить ее всем совокупным историческим опытом народа, стремящегося быть господином самого себя, сувереном, почитающим трансцендентного Бога как духовного отца и любящим свою семейную традицию как духовную мать. Без идеологии нация перестает быть нацией, парализуя свою политическую волю и безропотно отдавая власть, и рискует вовсе прекратить свое историческое бытие даже как народ, не воспроизводя свою национальную мифологию в политической сфере» $[13$, c. 207]. 
Нам представляется, что социальная мифология имеет двоякий характер, и более правильно говорить о ее конструктивно-деструктивной роли в жизни общества. Утверждая это, мы тем более соглашаемся и с оценкой неоднозначной роли мифологии в политической сфере. В частности, К.Ф. Завершинский отмечает, что «...авторы могут расходиться в понимании "позитивного" и "негативного” влияния процесса политической мифологизации. Одни авторы подчеркивают позитивную роль политического мифа в обеспечении исторической преемственности в формировании и поддержании политической идентичности, другие тяготеют к критике негативных (манипулятивных) последствий использования мифологизации политической реальности как стратегии политического доминирования элит, порождающей патологии массового политического сознания» [4, с. 18-19].

Как и в случае с обществом в целом, лучше понять значение социальной мифологии позволяет рассмотрение функций последней. Интересным в этом смысле представляется указание О.Ю. Малиновой на политические функции мифов: мифы как когнитивные схемы, облегчающие восприятие реальности за счет упрощения и селекции того, что вписывается в освоенные смысловые модели; мифы как неотъемлемый элемент политики идентичности; мифы как фактор легитимации власти и оправдания ее действий; мифы как средство формирования солидарности, в том числе и в условиях отсутствия консенсуса; мифы как «лекарство» в условиях кризисов [7, с. 15-19].

Следует отметить, что отмеченные политические функции мифов, очевидно, носят конструктивный заряд, но, как показывает политическая практика, это далеко не всегда приводит к позитивным результатам. Имеет место именно двойственность социальной, в частности политической, мифологии. Так, миф как фактор легитимации власти, может, достигнув небывалого расцвета в тоталитарных режимах, одновременно оказаться неуправляемым орудием в политической борьбе.

Выделение Г.И. Мусихиным [9, с. 108$110]$ четырех функций политического мифа упорядочивания, смыслонаделения (обоснования), интеграции и легитимации / делеги- тимации - лишь подтверждает, в более практическом плане, разделяемую нами социально-философскую парадигму осмысления функций социальной мифологии, где основными функциями социальной мифологии являются онтологическая, гносеологическая, аксиологическая и праксиологическая. При этом отмеченные функции политического мифа можно соотнести с основными функциями социальной мифологии следующим образом: функцию упорядочивания с онтологической функцией, функцию смыслонаделения (обоснования) - с гносеологической, функцию интеграции - с аксиологической, функции легитимации / делегитимации - с праксиологической (практической).

Концентрируясь на роли социальной мифологии в политике, можно сделать следующее обобщение: ключевое значение в политике приобретает легитимирующая функция мифа в силу прежде всего природы политической сферы как поля практического столкновения интересов и практического претворения идей в жизнь. Легитимирующая функция мифа, по мнению Г.И. Мусихина, наиболее отчетливо проявляется в ходе национальногосударственного строительства [9, с. 109]. Это обстоятельство позволяет нам в дополнение к отмеченным функциям политического мифа и социальной мифологии выделить прогностическую функцию (функцию развития, проектную функцию). Можно даже сказать, что политическая сфера дает жизнь прогностической функции социальной мифологии, выступающей как реальное выражение всех основных функций социальной мифологии в политике. Кроме того, открывается пространство для сравнения мифологии и утопии. Определяя утопию как разновидность рационализированного социального мифа, следует сделать акцент на темпоральном измерении: утопия представляет собой также и совокупность наиболее востребованных в определенный период времени мифологем о будущем устройстве общества. То есть утопия - это определенным образом рационально сконструированная проекция актуальных в настоящем мифологем в будущее.

Провозглашая развитие, изменение, мифы и идеологии и сами сталкиваются с быстро меняющимся обществом. Более того, 
само содержание идеологии может меняться: в частности, в последнее время появляются так называемые молекулярные идеологии [15], делающие акцент на конкретных направлениях деятельности (наличие таких узконаправленных идеологий и политических движений лишь подтверждает идеи Ж.-Ф. Лиотара [6] о закате метанарраций). То есть идеология может «встречать» перемены в сферах жизни общества, сама находясь в измененном состоянии, что справедливо и для социальной мифологии.

Перемены в общественной жизни ставят перед идеологией и социальной мифологией ряд вопросов: каким образом идеология может способствовать дальнейшему развитию общества; почему в периоды социальных трансформаций активизируется мифотворчество; учитывает ли государственная идеология кризисные состояния общественного сознания? Вопросов много, но несомненно, что общественный запрос на новую социальную мифологию и, возможно, идеологию должен ощущаться прежде всего политическими элитами и трансформироваться в осязаемые программы и конкретные действия.

\section{ПРИМЕЧАНИЕ}

${ }^{1}$ Статья подготовлена при поддержке гранта РФФИ 17-33-01056 а2 «Мифы о прошлом в современной медиа-среде: практики конструирования, механизмы воздействия, перспективы использования».

\section{СПИСОК ЛИТЕРАТУРЫ}

1. Барт, Р. Мифологии / Р. Барт. - М. : Изд-во им. Сабашниковых, 2004. - 320 с.

2. Гирц, К. Интерпретация культур / К. Гирц. М. : РОССПЭН, 2004. - 560 c.

3. Грицанов, А. А. Идеология / А. А. Грицанов // Новейший философский словарь. - Минск : Книжный дом, 2003. - С. 405-406.

4. Завершинский, К. Ф. Политический миф в структуре современной символической политики / К. Ф. Завершинский // Вестник Санкт-Петербургского университета. Серия 6, Политология. Международные отношения. - 2015. - Вып. 2. - С. 16-25.

5. Линченко, А. А. «Живите тыщу лет, товарищ Сталин...» : Трансформация мифологии образов И.В. Сталина в современной российской исто- рической памяти / А. А. Линченко, А. Г. Иванов // Диалог со временем. - Вып. 59. - М. : ИВИ, 2017. С. 116-135.

6. Лиотар, Ж.-Ф. Состояние постмодерна / Ж.-Ф. Лиотар. - М. : Институт экспериментальной социологии ; СПб. : Алетейя, 1998. - 160 с.

7. Малинова, О. Ю. Миф как категория символической политики / О. Ю. Малинова // Символическая политика : сб. науч. тр. / ред. кол.: О. Ю. Малинова (гл. ред.) [и др.]. - Вып. 3. Политические функции мифов. - М. : ИНИОН РАН, 2015. - С. 5-24.

8. Маркс, К. Немецкая идеология / К. Маркс // Экономическо-философские рукописи 1844 года и другие ранние философские работы. - М. : Академический Проект, 2010. - С. 388-472.

9. Мусихин, Г. И. Политический миф как разновидность политической символизации / Г. И. Мусихин // Общественные науки и современность. 2015. - № 5. - C. 102-117.

10. Оботурова, Г. Н. Миф в структуре познания и деятельности : автореф. дис. ... д-ра филос. наук / Оботурова Галина Николаевна. - Вологда, 1999. - 41 с.

11. Орлов, С. Б. Мифологема «Сталин». Образ вождя как системообразующий фактор российского общественного сознания / С. Б. Орлов, Д. В. Чернышков // Свободная мысль. - 2011. № 12. - С. 95-102.

12. Первушина, В. Н. Идеология в современной России / В. Н. Первушина // Вестник Воронежского государственного университета. Серия «Философия». - 2015. - № 2. - С. 132-139.

13. Полосин, В. С. Миф. Религия. Государство / В. С. Полосин. - М. : Ладомир, 1999. - 440 с.

14. Флад, К. Политический миф. Теоретическое исследование / К. Флад. - М. : Прогресс-Традиция, 2004. - 264 с.

15. Шварцмантель, Д. Идеология и политика / Д. Шварцмантель. - Харьков : Гуманитарный Центр, 2009. - 312 с.

16. Bottici, C. A Philosophy of Political Myth / C. Bottici. - Cambridge : Cambridge University Press, 2007. -286 p.

17. Lincoln, B. Theorizing Myth: Narrative, Ideology and Scholarship / B. Lincoln. - Chicago : The University of Chicago Press, 1999. - 313 p.

18. Malesevic, S. Identity as Ideology: Understanding Ethnicity \& Nationalism/S. Malesevic. Hampshire ; New York : PALGRAVE MACMILLAN, 2006. -253 p.

19. Seliger, M. Ideology and Politics / M. Seliger. London : Alien \& Unwin, 1976. - 352 p.

20. Shteynman, M. Political Myth and Political Glory: Shaping Media Reality/M. Shteynman // Russian Sociological Review. - 2016. - Vol. 15, № 4. - P. 96-113.

21. Tudor, H. Political myth / H. Tudor. - New York, London : Praeger Publishers, Inc., 1972. - 157 p. 


\section{REFERENCES}

1. Barthes R. Mifologii [Mythologies]. Moscow, Sabashnikovs Publ., 2004. 320 p.

2. Geertz C. Interpretatsiya kultur [The Interpretation of Cultures]. Moscow, ROSSPEN Publ., 2004. 560 p.

3. Gritsanov A.A. Ideologiya [Ideology]. Noveyshiy filosofskiy slovar [The Newest Philosophical Dictionary]. Minsk, Knizhnyy Dom Publ., 2003, pp. 405-406.

4. Zavershinskiy K.F. Politicheskiy mifv strukture sovremennoy simvolicheskoy politiki [Political Myth in the Structure of Modern Symbolic Politics]. Vestnik Sankt-Peterburgskogo universiteta. Seriya 6, Politologiya. Mezhdunarodnye otnosheniya, 2015, vol. 2, pp. 16-25.

5. Linchenko A.A., Ivanov A.G. «Zhivite tyshchu let, tovarishch Stalin...» : Transformatsiya mifologii obrazov I.V. Stalina v sovremennoy rossiyskoy istoricheskoy pamyati ["Live a Thousand Years, Comrade Stalin...": Transformation of Mythology of I.V. Stalin's Images in the Contemporary Russian Historical Memory]. Dialog so vremenem [Dialogue with Time]. Moscow, IVI Publ., 2017, vol. 59, pp. 116-135.

6. Lyotard J.-F. Sostoyanie posmoderna [The Postmodern Condition]. Moscow, Institut eksperimentalnoy sotsiologii Publ.; Saint Petersburg, Aleteya Publ., 1998. 160 p.

7. Malinova O.Yu. Mif kak kategoriya simvolicheskoy politiki [Myth as a Category of Symbolic Policy]. Simvolicheskaya politika. Kyp. 3. Politicheskie funktsii mifov [Symbolic Policy. Vol 3. Political Functions of Myths]. Moscow, INION RAN Publ., 2015, pp. 5-24.

8. Marx K. Nemetskaya ideologiya [The German Ideology]. Ekonomichesko-filosofskie rukopisi 1844 goda i drugie rannie filosofskie raboty [Economic and Philosophic Manuscripts of 1844 and Other Early Philosophic Works]. Moscow, Akademicheskiy Proekt Publ., 2010, pp. 388-472.
9. Musikhin G.I. Politicheskiy mif kak raznovidnost politicheskoy simvolizatsii [Political Myth as a Type of Political Symbolization]. Obshchestvennye nauki $i$ sovremennost, 2015, no. 5, pp. 102-117.

10. Oboturova G.N. Mif v strukture poznaniya $i$ deyatelnosti: avtoref. dis. ... d-ra filos. nauk [The Myth in the Structure of Cognition and Activity. Dr. philos. sci. abs. diss.]. Vologda, 1999. 41 p.

11. Orlov S.B., Chernyshkov D.V. Mifologema «Stalin». Obraz vozhdya kak sistemoobrazuyushchiy faktor rossiyskogo obshchestvennogo soznaniya ["Stalin" Mythologem. The Image of the Leader as a Backbone Factor of Russian Social Consciousness]. Svobodnaya mysl, 2011, no. 12, pp. 95-102.

12. Pervushina V.N. Ideologiya v sovremennoy Rossii [Ideology in Modern Russia]. Vestnik Voronezhskogo gosudarstvennogo universiteta. Seriya: Filosofiya, 2015, no. 2, pp. 132-139.

13. Polosin V.S. Mif. Religiya. Gosudarstvo [Myth. Religion. State]. Moscow, Ladomir Publ., 1999. 440 p.

14. Flood C. Politicheskiy mif. Teoreticheskoe issledovanie [Political Myth: A Theoretical Introduction]. Moscow, Progress-Traditsiya Publ., 2004. 264 p.

15. Schwarzmantel J. Ideologiya i politika [Ideology and Politics]. Kharkov, Gumanitarnyy Tsentr Publ., 2009. 312 p.

16. Bottici C. A Philosophy of Political Myth. Cambridge, Cambridge University Press, 2007. 286 p.

17. Lincoln B. Theorizing Myth: Narrative, Ideology and Scholarship. Chicago, The University of Chicago Press, 1999. 313 p.

18. Malesevic S. Identity as Ideology: Understanding Ethnicity \& Nationalism. Hampshire, New York, PALGRAVE MACMILLAN, 2006. 253 p.

19. Seliger M. Ideology and Politics. London, Alien \& Unwin, 1976. 352 p.

20. Shteynman M. Political Myth and Political Glory: Shaping Media Reality. Russian Sociological Review, 2016, vol. 15, no. 4, pp. 96-113.

21. Tudor H. Political myth. New York, London, Praeger Publishers, Inc., 1972. 157 p.

\section{Information about the Author}

Andrey G. Ivanov, Candidate of Philosophical Sciences, Associate Professor, Associate Professor, Department of Public Administration and Management, Lipetsk Branch of Russian Presidential Academy of National Economy and Public Administration, Internatsionalnaya St., 3, 398050 Lipetsk, Russian Federation, agivanov2@yandex.ru.

\section{Информация об авторе}

Андрей Геннадиевич Иванов, кандидат философских наук, доцент кафедры государственной, муниципальной службы и менеджмента, Липецкий филиал Российской академии народного хозяйства и государственной службы при Президенте Российской Федерации, ул. Интернациональная, 3, 398050 г. Липецк, Российская Федерация, agivanov2@yandex.ru. 